\title{
QUAL É A FORMA DA TERRA? REFLEXÕES SOBRE ATIVIDADES DE ASTRONOMIA EM UM CURSO DE EXTENSÃO
}

\author{
Roberta Cheisa Bartelmebs \\ Universidade Federal do Paraná \\ betachiesa@gmail.com \\ João Batista Siqueira Harres \\ Pontifícia Universidade Católica do Rio Grande do \\ Sul \\ joao.harres@pucrs.br
}

Michelle Mackmillan Ballester Rede Particular de Educação Palotina msmackmillan@yahoo.com.br

Simone Maria Ferreira Ikert Rede Particular de Educação Palotina simone_ikert@hotmail.com

Resumo: O presente trabalho relata a realização de duas atividades com crianças de $4^{\circ}$ e $5^{\circ}$ anos do Ensino Fundamental sobre conteúdos de Astronomia. Essas atividades são decorrentes de um Curso de Extensão sobre Metodologias para o ensino de Astronomia nos anos iniciais. O curso ocorreu no período de março a julho e 2015, para professores da Educação Básica em um município da região Oeste do Estado do Paraná. No curso enfatizaram-se metodologias que levassem em conta as ideias dos alunos sobre conteúdos de Astronomia presentes no currículo dos anos iniciais da Educação Básica. Discute-se a importância de conhecer as ideias dos alunos para propor atividades didáticas condizentes com seus níveis de compreensão do conteúdo. Da mesma forma, enfatiza-se a necessidade de os professores repensarem constantemente suas práticas com relação ao ensino de ciências, especialmente nos anos iniciais do Ensino Fundamental.

Palavras-chave: Ensino de Ciências. Astronomia. Ideias dos alunos.

\section{WHICH IS THE FORM OF THE EARTH? REFLECTIONS ABOUT AN ACTIVITY OF ASTRONOMY IN A COURSE OF EXTENSION}

Abstract

The present work tells the accomplishment of two activities with children of 4th and 5th years of the Fundamental Teaching, on Astronomy contents. Those activities are current of a Course of Extension on Methodologies for the Astronomy teaching in the initial years. The course happened in the period of March to July and 2015, for teachers of the Basic Education in a municipal district of the West area of the Paraná State. In the course methodologies were emphasized that took into account the student's ideas, on contents of Astronomy, presents in the curriculum of the years begin of the Basic Education. The importance is discussed of knowing the student's ideas to propose suitable didactic activities with their levels of understanding of the content. In the same way, the teachers' need is emphasized to rethink their practices constantly regarding the science teaching, especially in the beginning years of the elementary school. Keywords: Science Education. Astronomy. The student's' ideas.

\section{¿CUÁL ES LA FORMA DE LA TIERRA? REFLEJOS SOBRE UNA ACTIVIDAD DE ASTRONOMÍA EN UN CURSO DE EXTENSIÓN UNIVERSITARIA}

\section{Resumen}

En este trabajo se describe la realización de dos actividades sobre el contenido de la Astronomía con niños de 4 y 5 años de la escuela primaria, sobre el contenido de la Astronomía. Estas actividades hacen parte de un Curso de Extensión sobre metodología de enseñanza de la Astronomía en la primaria. El curso ocurrió en marzo y julio del año de 2015. En este curso se enfatiza metodologías que tengan en cuenta las ideas de los alumnos sobre contenidos de astronomía presentes en los planes de estudios de los primeros años de la educación básica. Se argumenta por la importancia de conocer las ideas de los alumnos para proponer actividades educativas acordes a su nivel de comprensión de los contenidos. Del mismo modo, hacemos hincapié en la necesidad de que los profesores reflexionen constantemente sobre sus prácticas respecto a la enseñanza de las ciencias, sobre todo en los primeros años de la escuela primaria.

Palabras clave: Enseñanza de las Ciencias. Astronomía. Ideas de los alumnos. 


\title{
APRESENTAÇÃO E CONTEXTUALIZAÇÃO
}

\begin{abstract}
Dois homens chegaram a um buraco no céu. Um pediu ao outro ajuda para se erguer até a abertura. Mas era tão bonito o céu que o homem que espiou pela beirada esqueceu tudo, esqueceu o companheiro a quem tinha prometido ajudar a subir e simplesmente saiu correndo para entrar em todo esplendor celeste. (Poema esquimó do início do séc. XX, retirado de SAGAN, p. 42, 2006).
\end{abstract}

Desde muito tempo, o céu tem despertado um sentimento de curiosidade na humanidade. Conhecer os segredos das estrelas, sua composição, existência e destino são metas que aos poucos têm sido atingidas. A beleza de uma noite estrelada, a contemplação em que ela nos permite ficar, diante da grandeza da imensa escuridão, também faz com que as crianças pequenas tenham desejos por aprender sobre as "coisas" ligadas ao céu.

Assim, ensinar Astronomia é muito importante para os anos iniciais por duas razões principais. A primeira é a motivação estética. Assim como Caniato (1974, p. 39), também acreditamos que: "O estudo do Céu sempre se tem mostrado de grande efeito motivador, como também dá ao educando a ocasião de sentir um grande prazer estético ligado à ciência: o prazer de entender um pouco do Universo em que vivemos".

A segunda razão é o fato de que, através do seu ensino, é possível ampliar os horizontes dos alunos e professores, para que cada vez mais possam ler a realidade a sua volta, permitindo-se questionar e buscar respostas. Isso motivou o oferecimento de um curso extensão sobre ensino de Astronomia para professores dos anos iniciais do Ensino Fundamental proporcionando uma experiência diferenciada de formação continuada e, ao mesmo tempo, possibilitar uma vivência estética ligada à Ciência.

Neste artigo, apresentamos os resultados de atividades deste curso de extensão realizadas por professores e depois desenvolvidas em sala de aula, com crianças de $4^{\circ}$ e $5^{\circ}$ anos do Ensino Fundamental nas quais foram exploradas as suas concepções acerca da forma da Terra. Inicialmente, participaram do curso de extensão quinze professoras da rede pública e privada de um município do Oeste do Paraná. No entanto, permaneceram até o final do curso apenas seis professoras, sendo que cinco delas atuam na rede pública municipal e uma na rede particular de ensino. As atividades analisadas foram elaboradas conjuntamente pelo grupo de professores e aplicadas por eles em suas respectivas turmas.

O objetivo principal do curso de extensão foi o de possibilitar aos professores um espaço de reflexão sobre suas práticas, especialmente com relação ao ensino de Astronomia. A proposta visava uma evolução conceitual dos professores com relação a suas concepções epistemológicas, didáticas e científicas. Para esse fim, o trabalhou pautou-se na compreensão das ideias dos alunos, 
Qual é a forma da terra? Reflexões sobre atividades de astronomia em um curso de extensão

promovendo espaços na sala de aula para que as crianças pudessem expor o que pensam sobre conteúdos de Astronomia.

\section{O CURSO “METODOLOGIAS PARA O ENSINO DE ASTRONOMIA"}

O curso de extensão "Metodologias para o ensino de Astronomia nos anos iniciais do Ensino Fundamental" foi realizado de março a junho de 2015 em um município da região Oeste do estado do Paraná. Foram oferecidos oito encontros quinzenais com duração média de $2 \mathrm{~h}$ a 3hs cada.

Este curso foi oferecido na modalidade extensão por entendermos que todas as ações universitárias devem estar vinculadas ao tripé: Ensino, Pesquisa e Extensão, tanto na graduação quanto na pós-graduação. Assim como afirma Boaventura de Sousa Santos (2004, s/p):

\footnotetext{
Numa sociedade cuja quantidade e qualidade de vida assenta em configurações cada vez mais complexas de saberes, a legitimidade da universidade só será cumprida quando as atividades, hoje ditas de extensão, se aprofundarem tanto que desapareçam enquanto tais e passem a ser parte integrante das atividades de investigação e de ensino.
}

De acordo com o Plano Nacional da Extensão (BRASIL, 2014), existem quatro eixos principais que sustentam as ações de extensão no âmbito das universidades brasileiras: Impacto e transformação; Interação dialógica; Interdisciplinaridade e Indissociabilidade ensino - pesquisa extensão. Assim, nossa principal motivação foi a de promover a interação entre Universidade e Comunidade Escolar. Além disso, o curso de extensão foi a via que permitiu criar um grupo coeso, comprometido com sua formação continuada.

O Curso foi oferecido em parceria entre uma Universidade Federal do Oeste do Paraná e a Secretaria de Educação municipal (SEMEC). Inicialmente houve 33 inscrições. A partir do segundo encontro se mantiveram seis professoras, cujo perfil é apresentado no Quadro 1, a seguir.

As desistências ocorreram principalmente por que o curso foi oferecido no período noturno por conta do turno de trabalho dos professores, e também porque a SEMEC não contabilizaria as horas do curso para pontuação na progressão de carreira, devido as especificidades do plano de carreira municipal dos professores. 
Qual é a forma da terra? Reflexões sobre atividades de astronomia em um curso de extensão

\begin{tabular}{|c|c|c|c|c|}
\hline Codinome & $\begin{array}{c}\text { Área de } \\
\text { Graduação }\end{array}$ & $\begin{array}{c}\text { Área de } \\
\text { Pós-graduação (strictu sensu) }\end{array}$ & Anos & $\begin{array}{c}\text { Tempo de sala de aula } \\
\text { (anos) }\end{array}$ \\
\hline Coruja & Pedagogia & (não tem) & $2^{\circ}, 4^{\circ}$ e $5^{\circ}$ & 20 \\
\hline Dina & Pedagogia & Didática e Metodologias de Ensino & $1^{\circ}$ ao $5^{\circ}$ & 33 \\
\hline Dona Margarida & Pedagogia & Psicopedagogia & $1^{\circ}$ ao $3^{\circ}$ & 20 \\
\hline Lua & Pedagogia & Educação & $1^{\circ}$ ao $5^{\circ}$ & 25 \\
\hline Mel & Pedagogia & Educação & $4^{\circ}$ e $5^{\circ}$ & 14 \\
\hline Pérola & Pedagogia & Neurociências para educadores & $4^{\circ}$ & 6 \\
\hline
\end{tabular}

Quadro 1 - Formação e atuação das professoras participantes do Curso de Extensão.

Fonte: Dados da Pesquisadora, 2015.

O fato de que todas as professoras possuíam mais de cinco anos de atividade docente, favoreceu uma boa troca de experiência entre as participantes, especialmente com relação a metodologias e atividades práticas.

A partir do curso pretendeu-se também ampliar o conhecimento sobre a Astronomia e seu ensino entre professores e futuros professores de Ciências no Ensino Fundamental, com base numa visão epistemológica construtivista. Nessa perspectiva, trabalhamos com o conceito de evolução conceitual conforme Harres e Krüger (2000), o qual procura: "Favorecer a evolução do conhecimento profissional dos professores, segundo uma hipótese de progressão orientada por um conhecimento profissional de referência com potencialidade para subsidiar um novo modelo didático pessoal (Idem, p. 119)".

O Curso de Extensão foi elaborado de acordo com o modelo de formação de professores proposto pelo Projeto Curricular Inovação e Renovação Escolar (IRES). O IRES é uma proposta de renovação escolar através de uma visão complexa da realidade, objetivando criar uma nova forma de pensar e agir na escola através do currículo, da didática, da avaliação e da metodologia. Inicialmente caracterizamos alguns problemas prático-profissionais (PPP) que, segundo García e García (2000, p.10),

\footnotetext{
Se admitimos que nossas concepções sobre a realidade evoluem na medida em que processamos informações novas, é evidente que a resolução de problemas tem grande importância para o conhecimento e a intervenção nessa realidade. De fato, todo problema dá lugar na formação, a partir das concepções preexistentes, a novas concepções melhor adaptadas com as circunstâncias esboçadas. Nesse sentido poderíamos dizer que aprendemos enquanto resolvemos os problemas que se originam em um entorno sempre diverso e mutante.
}

Entendemos que o trabalho a partir dos PPP favorece a evolução em direção a práticas mais contextualizadas, que permitem ao professor atingir um nível de evolução no qual seu modelo didático esteja baseado na investigação de sua própria ação em sala de aula. No Quadro 2 a seguir, explicitamos os PPP com os respectivos encontros em que seriam abordados. Os momentos inicial, intermediário e final de cada PPP referem-se a diferentes etapas no processo 
de complexificação da reflexão em cada PPP, nos quais são sugeridas ações e reflexões que possam auxiliar na evolução conceitual dos professores.

\begin{tabular}{|c|c|c|c|}
\hline PPP e Encontro & Momento Inicial & Momento Intermediário & Momento Final \\
\hline $\begin{array}{l}\text { PPP1 - Quais as ideias dos } \\
\text { alunos sobre temas de } \\
\text { astronomia? }\left(1^{\circ} \text { Encontro }\right)\end{array}$ & $\begin{array}{l}\text { Questionamentos sobre o } \\
\text { que os professores pensam } \\
\text { acerca das ideias dos alunos. }\end{array}$ & $\begin{array}{l}\text { Reflexões com base em } \\
\text { leituras sobre as ideias dos } \\
\text { alunos. }\end{array}$ & $\begin{array}{l}\text { Primeira versão do } \\
\text { questionário. }\end{array}$ \\
\hline $\begin{array}{l}\text { PPP2 - Como investigar as } \\
\text { ideias dos alunos sobre } \\
\text { conteúdos de astronomia? } \\
\left(2,3^{\circ} \text { e } 4^{\circ} \text { Encontro }\right)\end{array}$ & $\begin{array}{l}\text { Avaliação e discussão do } \\
\text { primeiro questionário. } \\
\text { Aprimoramentos a serem } \\
\text { feitos. }\end{array}$ & $\begin{array}{l}\text { Segunda versão do } \\
\text { questionário. }\end{array}$ & $\begin{array}{l}\text { Classificação das ideias } \\
\text { dos alunos, elaboração de } \\
\text { um inventário sobre as } \\
\text { ideias das crianças em } \\
\text { conteúdos de astronomia. }\end{array}$ \\
\hline $\begin{array}{l}\text { PPP3 - Que atividades } \\
\text { podem favorecer a evolução das } \\
\text { ideias dos alunos sobre } \\
\text { conteúdos de astronomia? } \\
\left(5^{\circ} \text { e } 6^{\circ} \text { Encontro) }\right.\end{array}$ & $\begin{array}{l}\text { Elaboração } \\
\text { planejamentos } \\
\text { conteúdos de astronomia a } \\
\text { partir do inventário das } \\
\text { ideias das crianças }\end{array}$ & $\begin{array}{l}\text { Primeira versão } \\
\text { planejamento atividade a } \\
\text { serem aplicadas em sala de } \\
\text { aula. }\end{array}$ & $\begin{array}{l}\text { Avaliação e discussão das } \\
\text { aulas aplicadas. }\end{array}$ \\
\hline $\begin{array}{l}\text { PPP4 - Como estruturar e } \\
\text { desenvolver uma unidade } \\
\text { didática de astronomia para os } \\
\text { anos iniciais do EF? } \\
\left(7,8^{\circ} \text { e } 9^{\circ} \text { Encontro }\right)\end{array}$ & $\begin{array}{lr}\text { Primeira } & \text { versão } \\
\text { planejamento } & \text { unidade } \\
\text { didática } & \\
\end{array}$ & $\begin{array}{l}\text { Socialização das unidades, } \\
\text { aplicações parciais em } \\
\text { algumas turmas dos anos } \\
\text { iniciais e avaliação. }\end{array}$ & $\begin{array}{l}\text { Planejamento de uma } \\
\text { unidade didática a partir } \\
\text { das ideias dos alunos } \\
\text { sobre conteúdos de } \\
\text { astronomia para os anos } \\
\text { iniciais. }\end{array}$ \\
\hline
\end{tabular}

Quadro 2 - Problemas Práticos Profissionais e detalhamento dos momentos didáticos do Curso de Extensão Fonte: Dados da Pesquisadora, 2015.

Não obstante, muitos pesquisadores tenham proposto contextos curriculares inovadores, é preciso compreender que os programas formadores precisam levar em conta as dificuldades que existem na mudança conceitual dos professores. Isso porque admitir que os alunos já possuam ideias ao chegarem à sala de aula, e que essas mesmas ideias acabam não sendo alteradas pelo ensino, implica em uma visão complexa e evolutiva das ideias dos alunos e, assim, das próprias ideias dos professores.

Em termos do ensino da Astronomia, fazem parte do currículo do município no qual as atividades foram realizadas conteúdos tais como fases da Lua, estações do ano, movimentos da Terra e Sistema Solar. Com relação aos recursos metodológicos aplicados no ensino de Astronomia, inicialmente percebemos que as professoras utilizavam muito material na forma de vídeos retirados da internet, e também livros disponíveis nas bibliotecas das escolas.

A partir disso, as professoras foram então, convidadas a refletir sobre suas aulas, e também a aprenderem novos conteúdos de Astronomia, concomitante com novas metodologias para ensinar esses temas. Para isso, oferecemos diversos tipos de materiais, como bola de isopor e lâmpada incandescente, planisférios, vídeos da internet e atividades de sequências didáticas sobre conteúdos de Astronomia.

Em cada novo encontros do curso eram abordados temas da Astronomia, conforme o interesse das professoras participantes. Além disso, durante os encontros eram discutidas 
possibilidades didáticas e pedagógicas para ensinar esses temas. Nossa intenção também foi a de perceber a evolução conceitual das professoras, com relação às suas concepções sobre ensino e aprendizagem de astronomia, e consequentemente, sobre suas concepções metodológicas.

\section{OS RESULTADOS E ANÁLISES DA NOSSA INTERVENÇÃO}

Durante os encontros, as professoras foram convidadas a realizarem atividades de leitura e discussão de textos, confecção de material didático para suas aulas e também a aplicarem alguns desses materiais para análise em conjunto. Por razões de espaço, neste artigo apresentamos as análises apenas duas das atividades desenvolvidas, nos encontros 4 e 5. Assim, o Quadro 3, a seguir, apresenta uma descrição das atividades desenvolvidas em cada desses encontros.

\begin{tabular}{|c|c|l|}
\hline Encontro & Momento & \multicolumn{1}{c|}{ Atividade } \\
\hline \multirow{3}{*}{$4^{\text {o }}$} & 1 & $\begin{array}{l}\text { Leitura e discussão da pesquisa de Nussbaum (1979) sobre a Terra como um corpo } \\
\text { cósmico. }\end{array}$ \\
\cline { 2 - 3 } & 2 & $\begin{array}{l}\text { Classificação das ideias dos alunos a partir da pesquisa realizada por Sharp (1996), } \\
\text { individualmente e posterior socialização no grande grupo. }\end{array}$ \\
\cline { 2 - 3 } & 3 & $\begin{array}{l}\text { Organização da aplicação das atividades nas escolas e na Universidade com os } \\
\text { alunos das turmas disponíveis. Encerramento: Socialização das escolas em que a } \\
\text { atividade pode ser desenvolvida. }\end{array}$ \\
\hline \multirow{5}{*}{$5^{\text {o }}$} & 1 & $\begin{array}{l}\text { Socialização das atividades aplicadas na turma a partir do inventário de crenças das } \\
\text { ideias dos alunos sobre conteúdos de astronomia. }\end{array}$ \\
\cline { 2 - 4 } & 2 & $\begin{array}{l}\text { Classificação das ideias dos alunos. Discussão de das ideias e elaboração de } \\
\text { propostas de intervenção didática nas aulas de Astronomia. }\end{array}$ \\
\cline { 2 - 3 } & 3 & Encerramento: Socialização das novas propostas. \\
\hline
\end{tabular}

Fonte: Dados da Pesquisadora, 2015.

Como exposto no Quadro 3, no quarto encontro, uma das atividades desenvolvidas foi a de identificação das ideias das crianças sobre a forma da Terra, a partir dos estudos desenvolvidos por Nussbaum e Novak (1976) sobre a forma da Terra. O conhecimento desse conceito, segundo Bartelmebs e Harres (2014) é um dos principais obstáculos epistemológicos a compreensão de outros conteúdos de Astronomia tais como estações do ano, fases da Lua, eclipses etc.

Nussbaum (1999, p. 260) apresenta as principais ideias das crianças sobre a forma da Terra, deixando claro que a ideia de Terra esférica não é óbvia por si mesma. É um conceito construído e que interfere na constituição de outras noções astronômicas:

Quando a criança muda sua ideia da forma da Terra de plana para esférica, seus conceitos acerca das características do espaço mudam com ela. O firmamento deixa de ser horizontal e o espaço "perde seu fundo", convertendo-se "espaçado" (sic) em todas as direções (Tradução dos autores, NUSSBAUM, 1999, p.261). 
Qual é a forma da terra? Reflexões sobre atividades de astronomia em um curso de extensão

Após a apresentação desse estudo, e dos diferentes níveis encontrados pelos autores, conforme Figura 1, a seguir, convidamos as professoras a classificarem alguns desenhos, retirados do trabalho de Sharp (1996) típicos das diferentes representações das crianças sobre uma pessoa em diferentes posições na Terra num dia de chuva, mostrados na Figura 2.

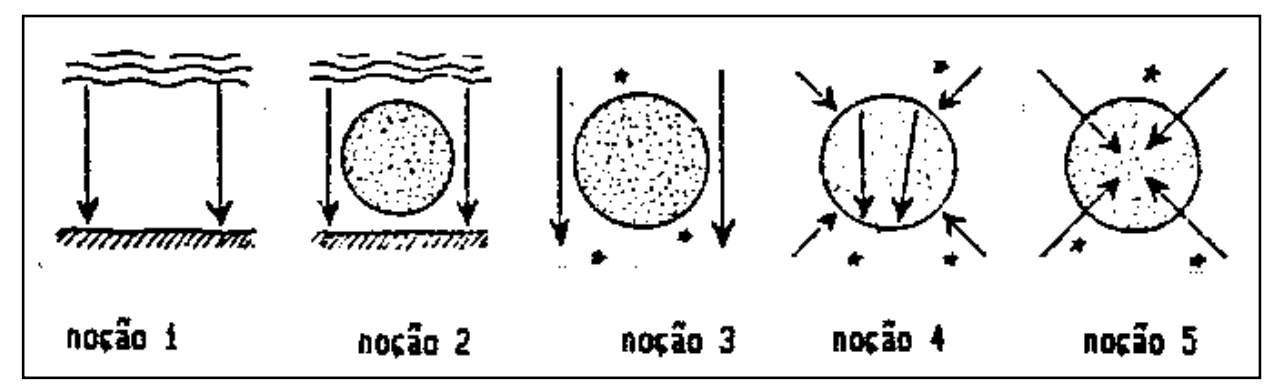

Figura 1 - Níveis de compreensão sobre a forma da Terra. Fonte: Nardi (1996) adaptado de Nussbaum (1979).

Entregamos uma folha para cada professora com a atividade a ser desenvolvida. Primeiro elas deveriam, individualmente, classificar as imagens conforme Figura 2, a seguir. Essa classificação deveria ser feita segundo as categorias propostas por Nussbaum (1979), conforme Figura 1, sobre a construção do conceito da forma da Terra e ordenando de acordo com o nível de complexidade das ideias representadas nos desenhos. Posteriormente poderiam trocar informações com as colegas e chegarem a um consenso sobre a classificação dessas ideias no grupo.

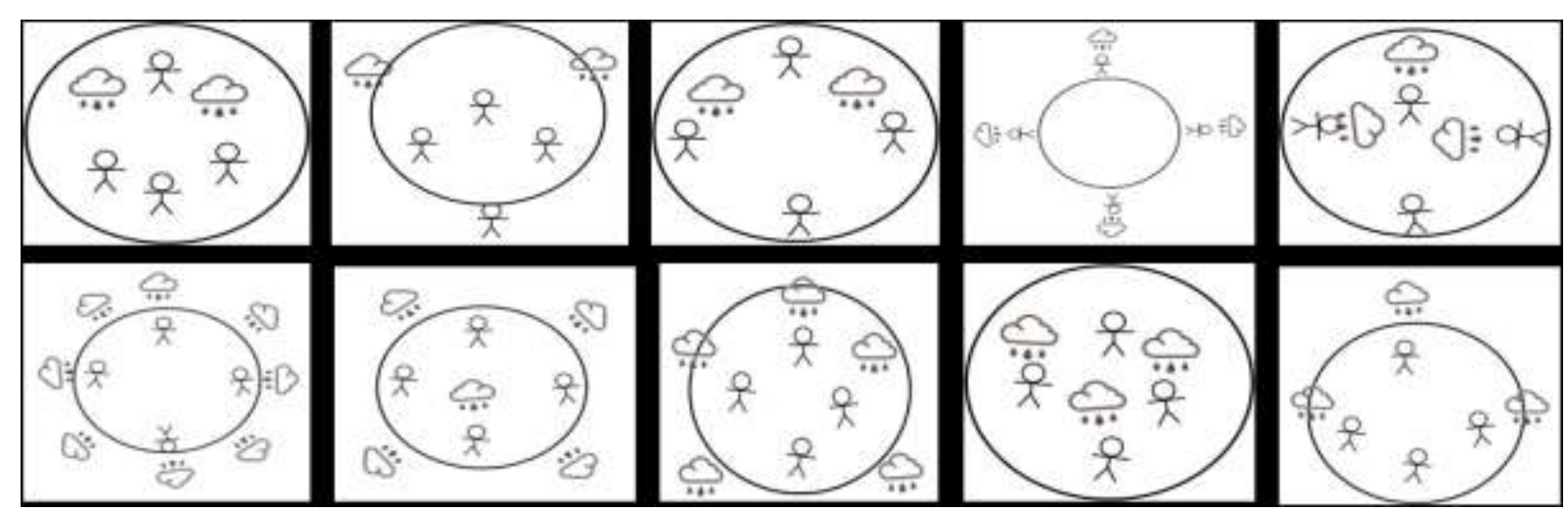

Figura 2 - Representações de pessoas em um dia de chuva na Terra Fonte: Adaptado de Sharp (1996).

Inicialmente as professoras ficaram admiradas com as diferentes ideias que as crianças possuem sobre a forma da Terra. Discutiam se isso também aconteceria com seus alunos. Especialmente no caso das ilustrações que representavam pessoas dentro da Terra. Ao final, as 
professoras haviam classificado de forma coletiva os desenhos, ficando categorizados conforme Quadro 4, a seguir:

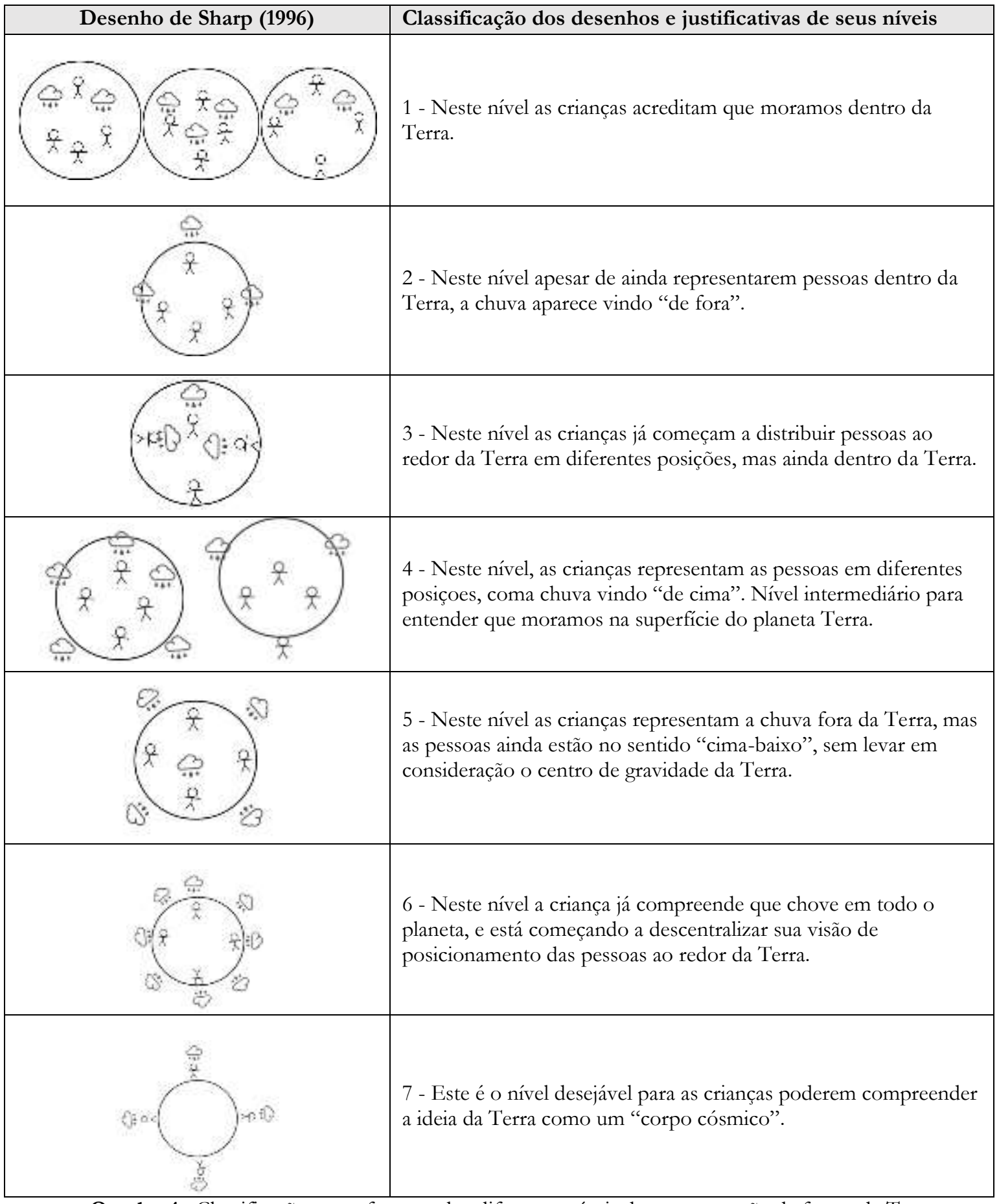

Quadro 4- Classificação as professoras dos diferentes níveis de representação da forma da Terra.

Fonte: Adaptado de Sharp (1996).

Diferente de Nussbaum (1976), as professoras classificaram mais de cinco níveis para as ideias representadas nas figuras. Isso porque, não havia sempre um consenso de quais seriam as características dos diferentes níveis, dessa forma, criaram-se mais 3 níveis, ficando então fixada a classificação final em 7 níveis. No entanto, a divergência maior foi causada entre os níveis 6 e 7 . 
Isso porque, para a professora Dina, Mel e Coruja, o desenho 6 representava o nível mais elevado da classificação desses desenhos. Elas entendiam que, nas representações do desenho do nível 7, as crianças estavam colocando tudo fora da Terra, e a chuva, segundo defendiam, não ocorre "fora", mas "dentro" da atmosfera. Depois de alguma discussão, e retomando a análise do texto de Nussbaum, chegou-se a um consenso de que o desenho do nível 7 era realmente o nível mais elevado de compreensão da forma da Terra, bem como da posição das pessoas ao redor do planeta.

Durante essa atividade, as professoras propuseram desenvolver esse mesmo trabalho com seus alunos para conhecerem suas ideias e compreensões sobre a forma da Terra. Assim, entre o quarto e quinto encontro do curso, realizamos atividades na forma de oficinas com os alunos de três turmas, conforme Quadro 5 a seguir.

\begin{tabular}{|c|c|c|c|}
\hline Professora & Ano & $\mathbf{N}^{\mathbf{o}}$ de alunos & Local \\
\hline Mel & $4^{\circ}$ & 32 & Escola \\
\hline Mel & $5^{\circ}$ & 30 & Escola \\
\hline Pérola & $5^{\circ}$ & 10 & Universidade \\
\hline
\end{tabular}

Quadro 5 - Turmas em que foram desenvolvidas atividades extensionistas.

Fonte: Elaborado pelos, 2015.

Os alunos do $4^{\circ}$ ano da professora Mel estavam trabalhando com o conteúdo do Sistema Solar, já os alunos do $5^{\circ}$ ano não possuem conteúdos de Astronomia no seu currículo, e estavam estudando o Sistema Nervoso Central. A atividade foi realizada inicialmente solicitando as crianças que fizessem um desenho, no círculo que lhes entregamos, de quatro pessoas em um dia de chuva na Terra.

Durante a realização da atividade, as crianças faziam perguntas sobre seus desenhos, ao que a professora sempre respondia que deveriam desenhar como achavam que acontecia. Após os alunos realizarem os desenhos, abriu-se um espaço para que comentassem suas dúvidas sobre Astronomia. As crianças aproveitaram o momento para fazerem várias perguntas relativas a diferentes conteúdos, como por exemplo: Porque o céu é azul? Porque as pessoas não caem da Terra? Algum asteroide já caiu na Terra? Essas e outras perguntas foram debatidas durante uma breve apresentação no quadro sobre o Sistema Solar. Percebemos que as crianças estavam entusiasmadas em fazer perguntas. O mesmo ocorreu com os alunos da professora Pérola. No entanto, a atividade ocorreu no espaço da Universidade porque haviam marcado uma oficina de observação do céu noturno. Aproveitou-se então o espaço para realizar uma breve apresentação sobre o Sistema Solar, como feita com os alunos de Mel. Foram exploradas e as perguntas que as crianças faziam, e ao final, solicitou-se que realizassem os desenhos. 
Qual é a forma da terra? Reflexões sobre atividades de astronomia em um curso de extensão

Depois disso, no quinto encontro do curso de extensão, as professoras avaliaram então os desenhos produzidos pelas crianças nas atividades da semana anterior. Nesse momento, elas fizeram uso dos seus conhecimentos acerca dos diferentes níveis de compreensão de um mesmo conteúdo conforme proposto por Nussbaum (1979). As professoras criaram quatro níveis, ao invés dos 5 propostos por Nussbaum, para classificar os desenhos dos alunos conforme Quadro 6. Essa diferença muito provavelmente tenha ocorrido porque havia certa homogeneidade entre as ideias das crianças, especialmente com relação aos níveis III e IV.

Para realizar a classificação dos níveis, elaboraram-se os seguintes critérios: a) O que esse aluno já sabe? b) O que esse aluno ainda não sabe? c) Como podemos promover evolução das ideias desse aluno? 


\begin{tabular}{|c|c|c|c|}
\hline & $\begin{array}{c}\text { a) O que já sabem? } \\
\text { b) O que ainda não } \\
\text { sabem? }\end{array}$ & Exemplos de representação & $\begin{array}{l}\text { O que podemos fazer } \\
\text { para } \\
\text { promover } \\
\text { evolução } \\
\text { desse nível? }\end{array}$ \\
\hline 常 & $\begin{array}{l}\text { a) Que a chuva cai; } \\
\text { Que moramos num } \\
\text { planeta; } \\
\text { Que existe chão, terra, } \\
\text { Sol, nuvens, } \\
\text { natureza. } \\
\text { b) Que moramos na } \\
\quad \text { superfície da } \\
\text { Terra; } \\
\text { O centro de gravidade; } \\
\text { Que não } \\
\text { sobreviveríamos dentro da } \\
\text { morando dento } \\
\text { Terra. }\end{array}$ & & $\begin{array}{l}\text { Mostrar o globo em } \\
\text { aula; } \\
\text { Utilizar um Atlas; } \\
\text { Utilizar o Google } \\
\text { Etilizar diferentes } \\
\text { materiais para } \\
\text { demonstrar às } \\
\text { crianças que é } \\
\text { possível morar } \\
\text { em outros } \\
\text { lugares da } \\
\text { Terra. }\end{array}$ \\
\hline Е & \begin{tabular}{llr} 
a) & \multicolumn{1}{c}{ Moramos na } \\
& superfície da \\
& Terra; A chuva \\
& vem das nuvens, \\
ou de "fora" da & \\
Terra. & \\
b) Não desenharam \\
pessoas a a \\
Ainda \\
redor da Terra; \\
possuem a \\
referência de \\
localização \\
centrada nas \\
posições acima \\
e abaixo.
\end{tabular} & & $\begin{array}{l}\text { Mostrar que existem } \\
\text { outros } \\
\text { continentes e } \\
\text { que pessoas } \\
\text { também } \\
\text { habitam esses } \\
\text { lugares. } \\
\text { Trabalhar a } \\
\text { proporção, } \\
\text { mostrando as } \\
\text { distâncias e os } \\
\text { tamanhos das } \\
\text { coisas com } \\
\text { relação ao } \\
\text { nosso tamanho } \\
\text { e dimensões. }\end{array}$ \\
\hline $\begin{array}{l}\Xi \\
\Xi \\
\bar{\Xi} \\
\bar{Z}\end{array}$ & $\begin{array}{lr}\text { a) } & \text { Moramos na } \\
\text { superfície da } \\
\text { Terra; A chuva } \\
\text { vem das nuvens, } \\
\text { ou de "fora" da } \\
\text { Terra. } \\
\text { b) Não desenharam } \\
\text { pessoas ao } \\
\text { redor da } & \text { Terra; } \\
\text { Ainda possuem } \\
\text { a referência de } \\
\text { localização } \\
\text { centrada nas } \\
\text { posições acima } \\
\text { e abaixo. }\end{array}$ & & $\begin{array}{l}\text { Mostrar que existem } \\
\text { outros } \\
\text { continentes e } \\
\text { que pessoas } \\
\text { também } \\
\text { habitam esses } \\
\text { lugares. } \\
\text { Trabalhar a } \\
\text { proporção, } \\
\text { mostrando as } \\
\text { distâncias e os } \\
\text { tamanhos das } \\
\text { coisas com } \\
\text { relação ao } \\
\text { nosso tamanho } \\
\text { e dimensões. }\end{array}$ \\
\hline
\end{tabular}




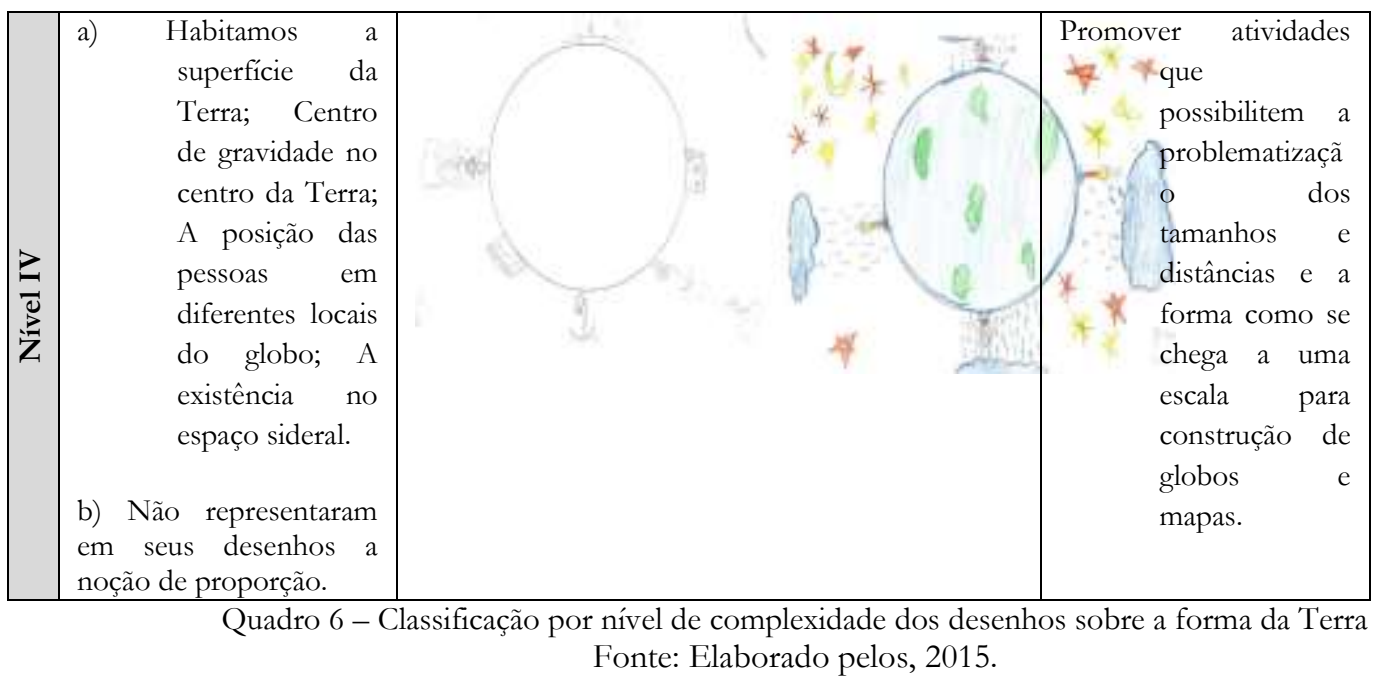

A partir desses questionamentos, procurou-se criar um ambiente que possibilitasse as professoras participantes explicitarem suas ideias sobre as ideias dos alunos. Durante a discussão da classificação as professoras perceberam as diferenças de conhecimentos de alunos de uma mesma classe, como podemos observar no extrato a seguir:

Professora Mel: Esse desenho bem aqui, mesma série, olha... coleguinhas da mesma sala, e fizeram bem diferentes ób, bem certinho, o fulaninho aqui do $5^{\circ}$ ano já não... (mostrando as diferenças entre os desenhos de alunos da mesma turma e de idades similares).

Compreender essas diferenças entre o pensamento dos alunos de uma mesma turma é um exercício muito rico para o professor. $\mathrm{Na}$ medida em que as professoras classificavam os desenhos, discutiam entre si algumas estratégias que poderiam utilizar em suas aulas para que todas as crianças pudessem chegar à compreensão de uma Terra como um "corpo cósmico" (NUSSBAUM, 1979). Ao realizar esses debates, as professoras discutiam sua própria formação inicial e continuada.

Não obstante, muitos pesquisadores tenham se preocupado em pensar contextos curriculares inovadores, é preciso compreender que os programas formadores precisam levar em conta as dificuldades que existem na mudança conceitual dos professores. Isso porque admitir que os alunos já possuam ideias ao chegarem à sala de aula, e que essas mesmas ideias acabam não sendo alteradas pelo ensino, implica em uma visão complexa e evolutiva das ideias dos alunos e, de mesma forma, das próprias ideias dos professores.

Nesse sentido, entendemos que as concepções de aprendizagem que os futuros professores possuem ou os seus conhecimentos epistemológicos e pedagógicos (BECKER, 1994) são o que intimamente se liga às suas compreensões sobre os conhecimentos prévios dos alunos, com relação aos conteúdos de ciências. Isso se relaciona com as estratégias didáticas que 
Qual é a forma da terra? Reflexões sobre atividades de astronomia em um curso de extensão

desenvolvem ao planejar uma aula, por isso tais estratégias merecem atenção especial nesta pesquisa que busca compreender a evolução conceitual dos futuros professores acerca do conteúdo e da forma como trabalhar esse conteúdo em sala de aula.

\section{CONSIDERAÇÕES FINAIS}

Ao encerrarmos as duas atividades neste texto relatadas, percebemos que as professoras puderam vivenciar um exercício de análise das ideias de seus alunos. Decorrente dessa primeira aproximação é possível que passem a utilizá-las em suas aulas. Além disso, nessa proposta de intervenção extensionista, foi possível levar um pouco do conhecimento científico e didático produzido na academia até as escolas de Ensino Fundamental do município.

Embora poucos professores tenham permanecido até o final das atividades, devido a outros cursos e demais demandas exigidas pelas escolas, os professores que conseguiram permanecer nos possibilitaram reconhecer a importância da atividade extensionistas na área da educação. Especialmente voltada para o ensino de Astronomia, área ainda carente tanto na formação inicial quanto continuada dos professores da Educação Básica. A extensão, aliada a pesquisa e ao ensino, permite à Universidade aproximar-se da realidade da escola. Esse movimento é uma via de mão dupla, pois, ao mesmo tempo em que a Universidade pode levar conhecimentos para os professores das escolas, recebe também, em contrapartida, experiências únicas que só podem ser vivenciadas no contato com os professores que atuam na Educação. Consideramos esse espaço privilegiado de construções, tanto para a evolução didático-conceitual das concepções dos professores, quanto para o crescimento dos pesquisadores e extensionistas da Universidade.

\section{REFERÊNCIAS}

BARTELMEBS, Roberta Chiesa; HARRES, João Batista Siqueira. Um estudo inicial sobre o que é preciso saber para compreender as estações do ano. In: Anais III Seminário Internacional em Educação em Ciências. SINTEC. Rio Grande, 2014.

BECKER, Fernando. Modelos pedagógicos e modelos epistemológicos. Educação e

Realidade, Porto Alegre, n 19, v.1, p. 89-96, 1994. 
Qual é a forma da terra? Reflexões sobre atividades de astronomia em um curso de extensão

BRASIL. REDE NACIONAL DE EXTENSÃO. Plano Nacional de Extensão Universitária. Disponível em: < http://www.renex.org.br/documentos/Colecao-Extensao-Universitaria/01Plano-Nacional-Extensao/Plano-nacional-de-extensao-universitaria-editado.pdf $>$ Acesso em Ago, 2014.

CANIATO, Rodolpho. Um projeto brasileiro para o ensino de física. Tese (Doutorado), Faculdade de Educação, UNICAMP, Campinas, 1974.

GARCÍA, Eduardo; GARCÍA, Francisco. Aprender investigando: Una propuesta metodológica basada en la investigación. $7^{a}$ ed. Sevilla: Diada, 2000.

HARRES, João Batista Siqueira; KRÜGER, Verno. Concepções prévias de professores de ciências sobre ensino: referente para a evolução de seus conhecimentos profissionais. In: Caderno Pedagógico, no 3, v. 1, p. 113-133, 2000.

NARDI, Roberto; CARVALHO, Ana Maria Pessoa de. Um estudo sobre a evolução das noções de estudantes sobre espaço, forma e força gravitacional do planeta Terra. In: Investigações em ensino de ciências, $n^{\circ}$ 2, v. 1, p. 132- 144, 1996.

NUSSBAUM, Joseph. Children's conceptions of the Earth as a cosmic body: a cross-age study. In: Science Education, v. 1, n. 63, p. 83-93, 1979.

La tierra como cuerpo cósmico. IN: DRIVER, Rosalind; GUESNE, Edith; TIBERGHIEN, Andrée. Ideas científicas en la infancia y la adolescencia. Madrid: Editora Morata, 1999.

; NOVAK, Joseph, D. An assessment of childrens concepts of the Earth utilizing structural interwiews. In: Science Education, v. 60, n. 4, p. 535-550, 1976.

SAGAN, Carl. O mundo assombrado pelos demônios: a ciência vista como uma vela no escuro. São Paulo: Companhia das Letras, 2006.

SANTOS, Boaventura de Sousa. A Universidade no século XXI: para uma reforma democrática e emancipatória da Universidade. São Paulo: Cortez, 2004.

SHARP, John G. Children's astronomical beliefs: a preliminar study of year 6 children in Southwest England. In: International Journal of Science Education, n. 6, v. 18, p. 685-712, 1996. 